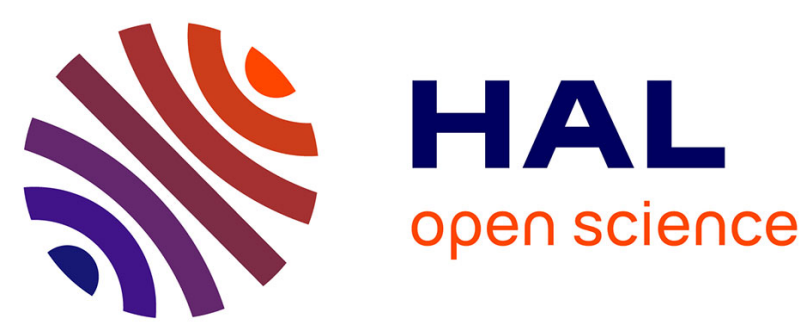

\title{
Enhanced Weld Penetrations In GTA Welding with Activating Fluxes Case studies: Plain Carbon \& Stainless Steels, Titanium and Aluminum
} Guillaume Ruckert, Nicolas Perry, Stéphane Sire, Surendar Marya

\section{- To cite this version:}

Guillaume Ruckert, Nicolas Perry, Stéphane Sire, Surendar Marya. Enhanced Weld Penetrations In GTA Welding with Activating Fluxes Case studies: Plain Carbon \& Stainless Steels, Titanium and Aluminum. THERMEC 2013, Dec 2013, United States. pp-202. hal-00941234

\author{
HAL Id: hal-00941234 \\ https://hal.science/hal-00941234
}

Submitted on 3 Feb 2014

HAL is a multi-disciplinary open access archive for the deposit and dissemination of scientific research documents, whether they are published or not. The documents may come from teaching and research institutions in France or abroad, or from public or private research centers.
L'archive ouverte pluridisciplinaire HAL, est destinée au dépôt et à la diffusion de documents scientifiques de niveau recherche, publiés ou non, émanant des établissements d'enseignement et de recherche français ou étrangers, des laboratoires publics ou privés. 


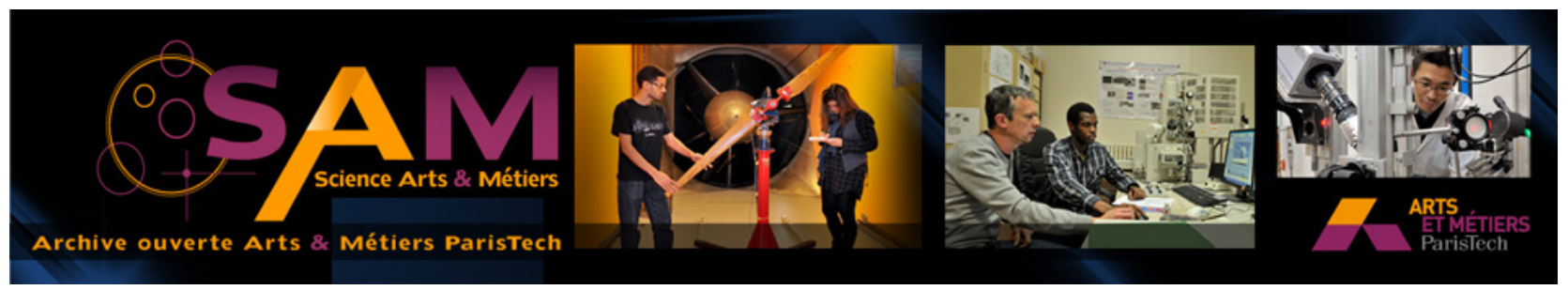

Science Arts \& Métiers (SAM)

is an open access repository that collects the work of Arts et Métiers ParisTech researchers and makes it freely available over the web where possible.

This is an author-deposited version published in: http://sam.ensam.eu

Handle ID: .http://hdl.handle.net/10985/7740

\section{To cite this version :}

Guillaume RUCKERT, Nicolas PERRY, Stephane SIRE, Surendar MARYA - Enhanced Weld Penetrations In GTA Welding with Activating Fluxes Case studies: Plain Carbon \& Stainless Steels, Titanium and Aluminum - 2013 


\title{
Enhanced Weld Penetrations In GTA Welding with Activating Fluxes Case studies: Plain Carbon \& Stainless Steels, Titanium and Aluminum
}

\author{
G. Rückert ${ }^{1, a}$ N. Perry ${ }^{2, b}, S . S^{3} e^{3, c}$, and S. Marya ${ }^{4, d *}$ \\ ${ }^{1}$ DCNS Research, CESMAN, Indret, 44620 LA MONTAGNE, FRANCE \\ ${ }^{2}$ Arts et Métiers ParisTech, I2M, UMR 5295, Esplanade des Arts et Métiers, 33405 TALENCE \\ Cedex, FRANCE, \\ ${ }^{3}$ LBMS, EA 4325, IUP Génie Mécanique, 6 avenue Victor le Gorgeu, CS 93837, 29238 BREST \\ Cedex 3, France, \\ ${ }^{4}$ Ecole Centrale, 1 rue de la Noë, 44072 Nantes Cedex, FRANCE \\ ${ }^{a}$ guillaume.ruckert@dcnsgroup.com, ${ }^{b}$ n.perry@i2m.u-bordeaux1.fr, \\ ${ }^{c}$ stephane.sire@univ-brest.fr, ${ }^{d}$ surendar.marya@ec-nantes.fr
}

\begin{abstract}
Flux applications prior to the convention Gas Tungsten Arc Welding (GTAW) is known to improve weld penetrations and improve process competitiveness. This paper summarizes the investigations on aluminum, plain carbon steels, stainless steels and titanium. The importance of flux composition, homogeneity and profile of its application are shown to be primordial in determining the weld depth to width ratio of weld pools. The mechanisms that lead to improved penetrations along with some industrial case studies are presented.
\end{abstract}

Key Words: ATIG, Weld penetrations, Steels, Titanium, Aluminum

\section{Introduction}

Gas Tungsten Arc Welding (GTA or TIG welding) has successfully been used ever since its invention as a reliable welding technique. Easy to implement in application with a comparatively low capital investment, the process yields cosmetic welds of excellent characteristics. However, due to low inherent weld penetrations at nominal currents, the process lacks productivity in comparison with other welding technologies on the market. For thickness over $3 \mathrm{~mm}$, multi-pass welds with filler additions remain mandatory. Attempts to improve penetrations by increasing welding current or reducing weld speeds generally remain ineffective. In fact, the weld pool widens with insignificant effect on penetration. It seems thus important to look for alternative means to improve GTA performance.

Flux for TIG welding efficiency improvements: ATIG (Activated TIG) \& FBTIG (Flux Bounded TIG). Theoretical studies supplemented with experimental investigations suggest that the weld penetration is dominated by surface tension temperature gradients over the pool [1,2]. The presence of some surface-active species that increase the melt surface tension with temperature induces thermo-capillary flows deep into the weld and results in deeper penetrations. As such, sulfur and to some extent oxygen in the pool has been suggested to produce deep and narrow welds. Increasing the arc power density through its constriction is an alternative route to improve weld penetration $[3,4]$.

Fluxes have long been used to finely tune weld metal chemistry, ensure arc stability and shielding in welding industry. However the application of flux coatings in GTAW is still a rare practice. Some of the reasons being lack of information on flux composition, its role in weld formation, probable loss of weld cosmetic and weld instability with variations in coating thickness. Fluxes can intervene in modifying drastically the weld formation in multiple ways notably by modifying surface tension, its temperature gradients and constricting the arc that would increase 
power density and consequently the weld penetration. The arc constriction itself is possibly attributed to:

- modified charge distribution created by elements with large electron cross-sections such as Oxygen, halides and fluorides;

- the creation of a conducting channel around the joint following flux vaporization in this hotter central region of the arc and to some extent;

- indirect effect of weld pool deformation in case of low surface tension melts. The central depression with curved sidewalls is propitious for arc localization and subsequent better heat exchange with the weld pool.

The above listed changes can intervene all together or one may be more predominant than others. From theoretical considerations, it may be postulated that one of the requirements for the flux to be effective is that its melting temperature should be close to that of the material and it should not form stable compounds with the molten pool that would badly affect weld cosmetic. Authors have thus investigated the effect of different coatings on plain carbon steels, stainless steels, titanium, and aluminum. Both continuous and gapped coatings have been explored and possible mechanisms that contribute to improved penetrations $(>7-10 \mathrm{~mm})$ are examined $[6,7,8,9]$. GTAW (or TIG), which when applied in conjunction with flux coating is designated as ATIG or activated TIG. Preliminary developments were first made in former Soviet Union and gained interest in western countries later when scientific information circulated by open exchanges. In ATIG process, the flux covers only a small proportion of the surface facing electrical around the joint. Flux coating may continuously cover the joint as in Fig. 1.a or discontinuous over a small width around the joint as in Fig. 1.b, the former is ATIG and the latter is called FBTIG or Flux bounded TIG. For better process stability, it is essential to ensure that it does not seep inside the joint and that its application is as uniform as possible. The flux is manually applied by brush and before application the flux ingredients are mixed in a solvent mostly acetone. After application, the flux is easily dried and is prerequisite for welding.

The paper will present a summary of results on the above-mentioned materials and examine future prospects. Some ongoing or proposed applications would be discussed.

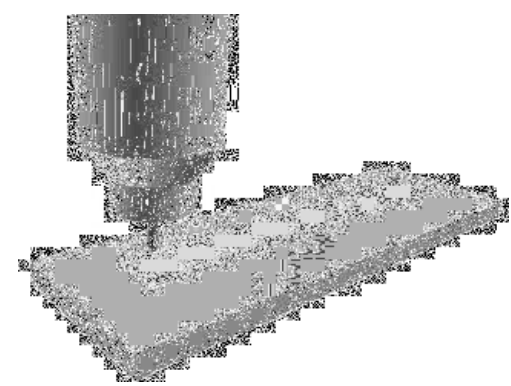

(a)

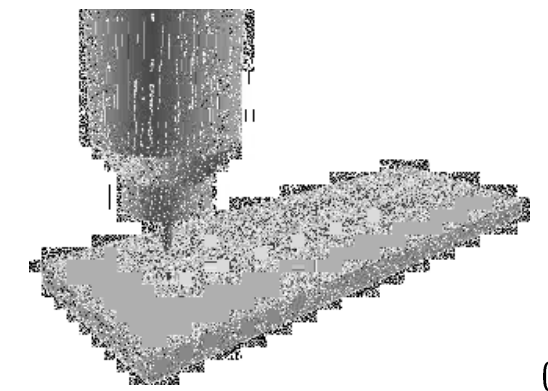

Fig.1. Flux disposition in ATIG (a) and FBTIG (b)

\section{Results and Discussion}

ATIG. One of the consequences, besides important increase of weld penetration observed on cut cross sections, can be seen directly on the arc profile and its intensity. Figure 2, shows variation of arc profile and its digitalized image as it goes from the non covered or TIG to the covered flux (ATIG arc). Soon as it enters the flux covered side, arc starts to increase in intensity and higher hear intensity zone is drawn close to the surface (Fig. 2.b) and at stabilization, plasma ejection from the weld pool with depressions in its free surface are seen (Fig. 2.c). These changes become more significant as the welding current is increases. The most significant observation is related to the depression of the weld pool, hardly visible in TIG at higher currents, but very prominent at higher ATIG currents. This suggests a confined arc on surfaces with flux coatings, implying a significant 
penetrations exceeding $7 \mathrm{~mm}$ have been obtained by a suitable combination of arc current and travel speed.

The flux developed by Perry et al. [4,5] for titanium alloys is composed of a blend of fluorides, though mono component $\mathrm{MgF} 2$ can be seen to be equally efficient except a minor change in weld cosmetic. In order to see if the increase in weld penetration is purely related to arc as seen from brighter arcs, bead on plate experiments with a defocused laser beam (Fig. 3) equally showed a subsequent increase in weld penetration when the surface was covered with a flux layer (Fig. 3b). In a mixed configuration (Fig. 3.c), penetrations became higher on non-coated side, which strongly indicates a surface tension driven flow as laser is in no way deflected as arc would be by an asymmetric disposition of a non-conducting flux reported later on here. This lends support that at least in case of flux proposed by Perry et al; surface tension did play some role in increasing weld penetrations via Marangoni type convection currents. However, the extent of each one of the possible mechanisms is difficult to ascertain.
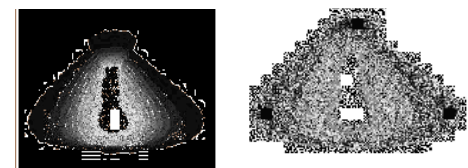

TIG Arc (a)

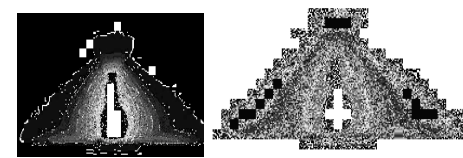

Entering Flux (b)

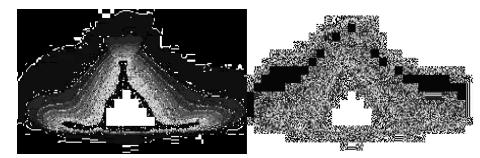

Stabilized ATIG Arc C

Fig. 2. Arc views and intensity profiles in going from TIG to ATIG, 100A, 15 cm/min, T-40 [4,5]

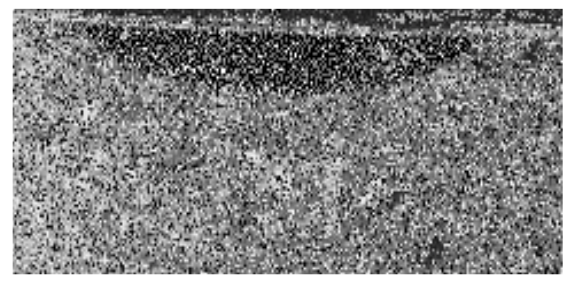

(a) Uncovered Plate

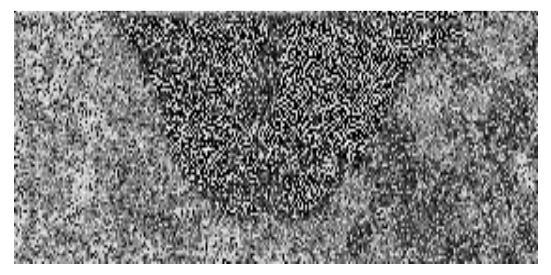

(b) Flux covered plate

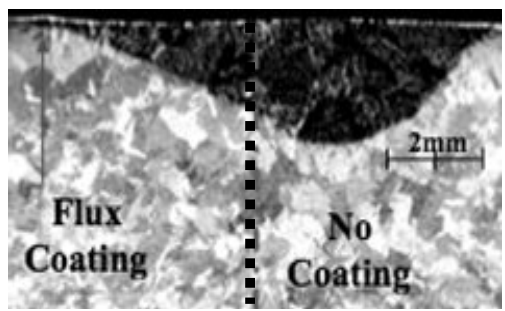

(c) Mixed Configuration

Fig. 3. Bead on plate weld pool penetrations with a defocused laser beam (T-40); Penetrations are weaker on flux side in a mixed configuration (c)

With manual flux application, it is very difficult to ensure its uniform application. Rückert et al. [6] investigated the effect of flux thickness in case of a 304 stainless steel where a $\mathrm{SiO} 2$ coating did increase weld penetrations by 50 to 75 percent in comparison to pure TIG at equivalent process parameters. The optimum flux thickness depends on the weld current and was found to vary from 40 to 70 microns as the current was increased from 100 to 150A. Beyond this optimum thickness, a rapid decline in weld penetrations is observed (Figure 4). With thicker coatings, the ATIG weld penetrations would not be significantly different from those observed on uncovered surfaces. The thickness effect explains the reason of variable bead penetrations observed when the flux is applied manually.

Silica is equally effective as activating TIG flux for plain carbon steels. As shown in Figure 5 for plain carbon steel, whatever the current level, the depth to width ratio with flux is superior for fluxcovered plates. At a given current, weld penetrations are virtually twice those with conventional TIG. Silica is a highly resistive material and its positive role in increasing weld penetration needs some further comments (Figure 5). Due to its higher resistance, it is expected that silica might destabilize the arc as it progresses from the uncovered to the coating side. This is effectively observed and schematically represented in Figure 6. As the arc progresses from the bare to the covered side, weld pool is seen to change from semi circular (Fig. 6.a) to a more triangular pool (Fig.6.d) i.e., the pool as seen from the front is narrowed in width. Weld points realized according to the schematics of the Figure 6 supplement these results from video observations. As the length of the arc into the coating increases, the molten pool is seen to become narrower, but more elongated opposite to the welding direction. These observations suggest that higher electric resistance of the 
arc continuously moves in the flux coating, the pool would be equally elongated as the back of the pool becomes uncovered by earlier passage of the arc. Arc tends to move to points where the resistance is lowest as further suggested by observations reported in Figure 8. Here, flux is applied only one side of the joint and arc tends to deviate towards the bare side. Observation of cross sections reveals comparatively higher penetration on the bare side, which in first instance may look contrary to the fact that ATIG penetrations are better than TIG at equivalent process parameters. In fact as the arc moves towards the bare side (Fig. 7.b) more heat is generated in the bare side and this possibly contributes to higher penetrations. Nevertheless, surface tension variations (lower on silica side) over the pool would also generate Marangoni flow away to the non-coated side. This heat transfer would generate wider and deeper pool on the non-coated side

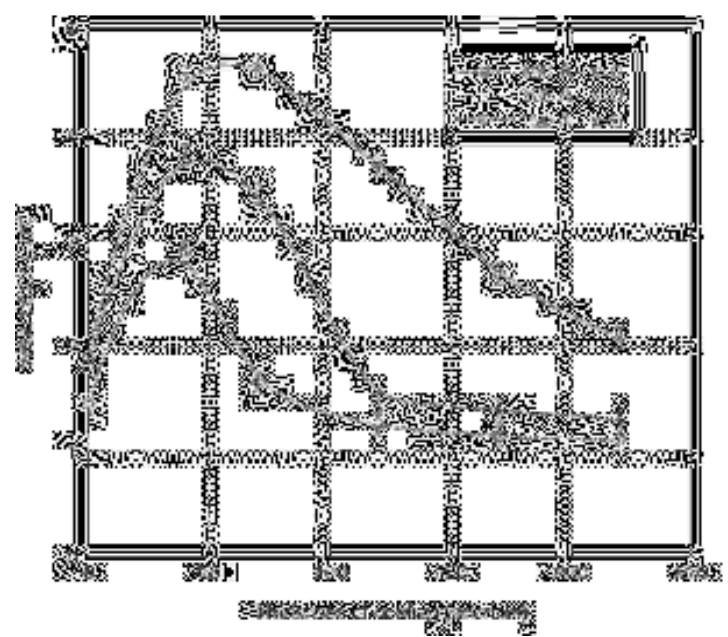

Fig.4 Effect of coating thickness (silica) on penetration, 304L steel [6]

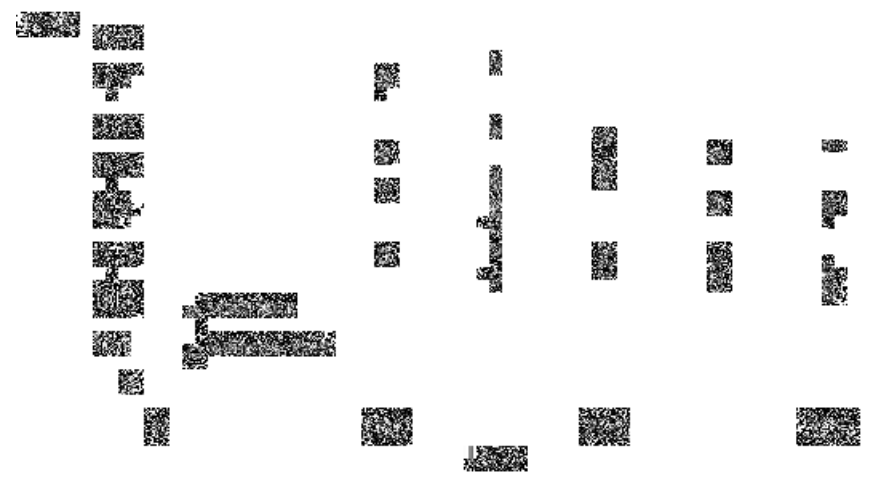

Fig.5 Evolution of D/W ratio with welding current with and without silica coatings [7]

Arc deviation away from flux is an important indicator of how its inherent tendency to choose the least resistive path may be implemented to increase its power density or constriction. In case of FBTIG developed by Sire et al. [7], a non-coated space around the joint, as in Figure 1.b, is managed such that the arc remains confined to this zone. Figure 9 suggests that a free surface in between the flux coatings gives equally well weld penetrations. A closer look of the etched sections further shows narrower heat affected zones with FBTIG (see Fig 9.b). Results reported by Ruckert [6] on the effect of coating thickness on weld penetration in ATIG and FBTIG showed that the latter is much more immune to coating thickness. In ATIG, before the arc stabilizes to create a conducting channel by fusion of the non-conducting coating, a large part of the energy is consumed just to create that conducting passage. Hence, the coating thickness becomes an important variable of the ATIG process. In FBTIG, this passage is pre generated and so the process performance is less sensitive to coating thickness.

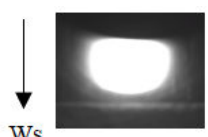

(a)

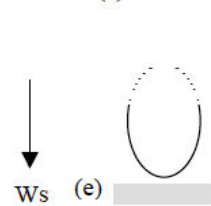

(b)

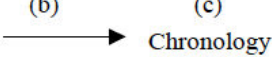

(f)

(g)

Fig.6. Still video captures with different arc positions (a to d) and schematic representation of weld pool (e to g) [7]

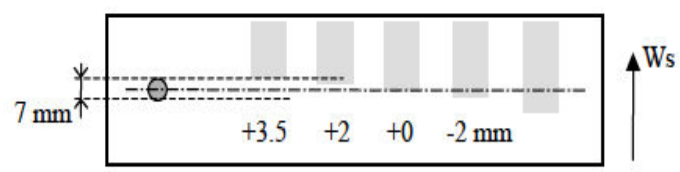

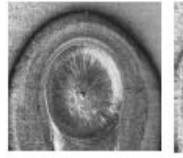

(a)

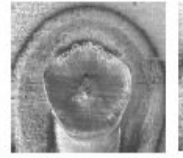

(b)

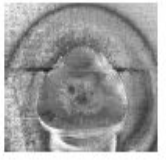

(c)

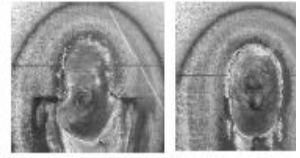

(d) (e)
Fig.7.Weld points as observed at different penetrations into flux coating [7] 


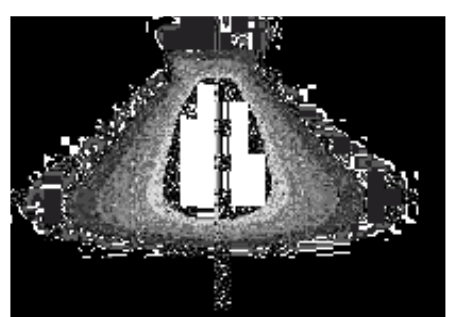

(a) TIG Arc

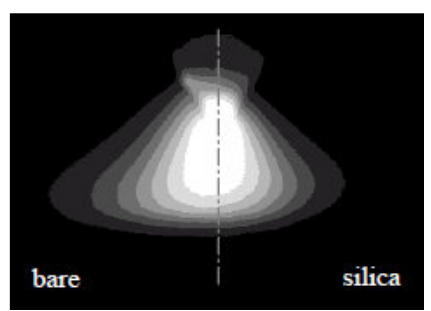

(b) TiG-ATIG Configuration

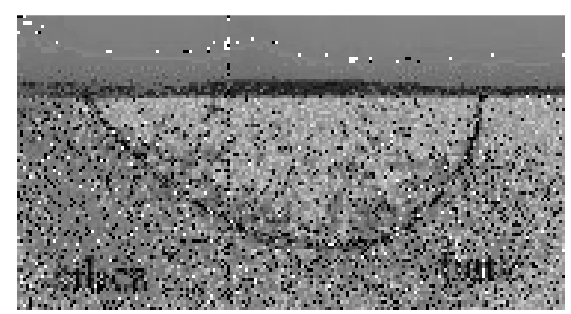

(c) TIG-ATIG Configuration

Fig.8. Effect of flux application on one side of the joint: Symmetric arc TIG (a), Arc deviation towards bare side, (b) and etched weld cross sections. Note higher penetrations on bare side [5]

FBTIG or flux bounded TIG. FBTIG is just another variant of activated TIG and seemingly more suited for manual application of flux coatings as more immune to coating thickness. Further in ATIG, it's pretty difficult to keep the flux out of the joint. Figure 9 shows on an Al 1050 plate, that FBTIG in AC mode gives very deep penetrations with $\mathrm{SiO} 2$ coating. In fact, because of the inherent aluminum oxide layer, DC TIG welding is inappropriate with argon shielding gas. With AC TIG, usually at nominal currents indicated for Figure 9 are very small. Besides current and welding speed, the gap in between the coatings on the two sides of the joint is an important process parameter. As this gap increases, the difference between TIG and FBTIG decreases as anticipated. Arc becomes less constrained as the gap between the coating increases [8]. Figure 10 shows that with FBTIG, arc is highly constrained with high intensity channel and the weld pool is depressed. The arc penetrates in to the joint and all this contributes to increased weld penetrations.

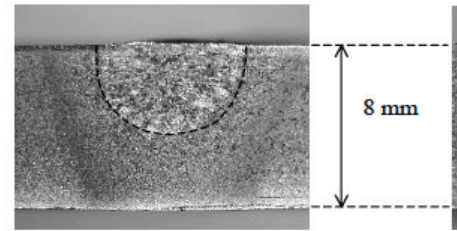

(a)

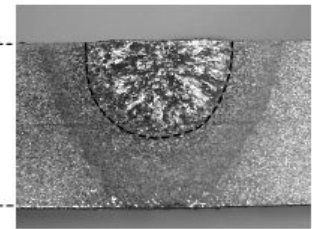

(b)

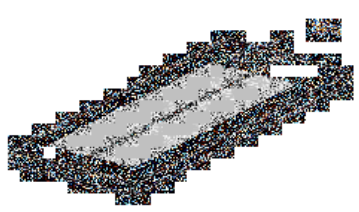

紋鼣

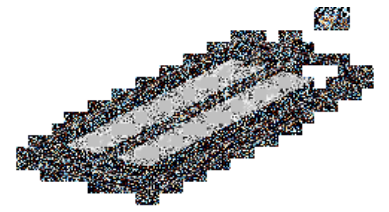

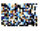

Fig.9. Comparative of weld pool penetrations on etched cross sections in ATIG(a) and FBTIG (b) configurations; 304 Steel, 150 A, 15 cm/min [7]

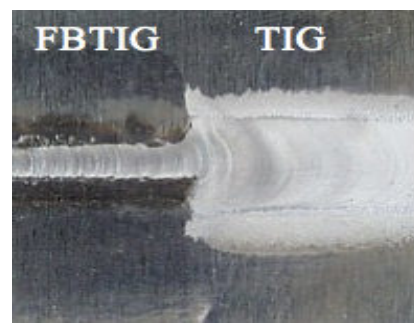

(a) Free surface,

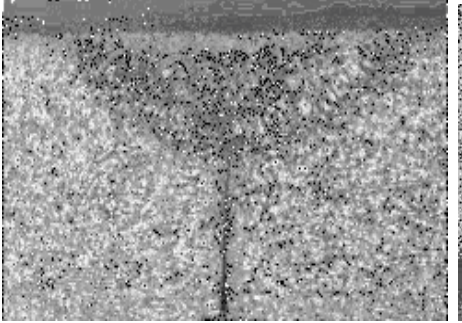

(b) AC-TIG,

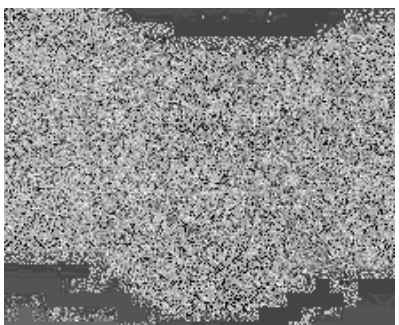

(c) FBTIG

Fig.10 (a) Narrowing of bead with FBTIG, significant increase in penetration with FBTIG, $175 \mathrm{~A}, 15 \mathrm{~cm} / \mathrm{min}$ on Al 1050 [8]

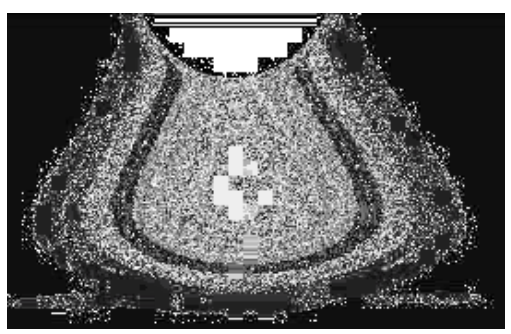

Fig.11 Stills of arc -AC TIG (a) and FBTIG (b), 150 A, 4mm gap between coatings [8]

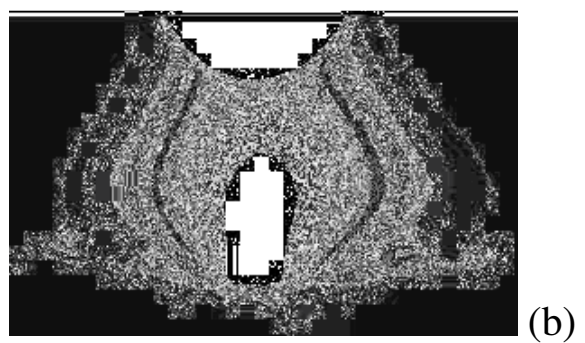

(b) 


\section{Conclusions}

Fluxes based on fluorides for Titanium and oxides (mostly silica) for plain carbon steels, stainless steels and aluminum have been tested in ATIG and FBTIG and mechanisms that contribute to enhanced weld penetrations are examined. In ATIG, a continuous flux coating, $15 \mathrm{~mm}$ wide is applied around the joint, whereas in FBTIG, an uncovered strip, 2 to $4 \mathrm{~mm}$ wide, and centered around the joint is managed. Fluxes are non-conducting in solid state and become conducting in liquid phase. This implies that in ATIG, arc needs to first melt the flux. Vaporized flux would modify electronic current density. Afterwards, ATIG arc operates on the created bare zone still surrounded by a non-melted flux coating. At this stage, difference between ATIG and FBTIG processes nearly vanishes. From energy considerations, FBTIG is more efficient as arc energy does not have to undercover the flux coating to pave way for a conducting channel on the metal surface. When the width of the uncovered zone in FBTIG is increased, arc becomes freer and weld penetrations are reduced to that of TIG process. The prerequisite of the creation of a conducting channel in flux coating implies that the coating thickness would become a critical parameter as identified here. Whatever the flux initial disposition, the video stills underline constricted highly intense arcs in ATIG and FBTIG configurations along with depressions in the weld pool. That alone is propitious for enhanced weld penetrations. All flux coatings tested here under are shown to produce improved weld penetrations when a defocused laser beam is used to simulate weld pool formation. This, along with asymmetric bead on plate weld profiles on specimens with coatings confined to one side of the ATIG arc, suggest a contribution from surface tension driven Marangoni type flow in the weld pool. However, the contribution from arc constriction and surface tension gradient driven flows has not been quantified. Further investigations are needed to elucidate some aspects described in this paper.

\section{References}

[1] P. Burgardt and C.R. Heiple Interaction between impurities and welding variable determining GTA weld shape, Welding Research Supplement, (1986), pp. 150s-155s

[2] K.C. Mills, B.J. Keene, Factors affecting variable weld penetration, Int. Materials Review, Vol. 35, (1990), pp. 185-216

[3] W. Lucas and D. Howse, Activating flux increasing the performance and productivity of the TIG and plasma processes, Welding \& Metal fabrication, Vol. 1(1996), pp.11-17

[4] N. Perry, S. Marya, E. Soutif, Study and development of flux enhanced GTA penetrations in a commercial grade titanium, 5th Int. Conf. On Trends in Welding Research, ASM/AWS Pine Mountains, Georgia, 1-5 June 1998, pp. 520-525

[5] N. Perry, Etude et développement de flux solides pour le soudage ATIG appliqué aux alliages de titane et aux aciers inoxydables, (2000), PhD Thesis, University of Nantes \& ECN (Fr)

[6] G. Rückert, B. Huneau, S.K. Marya, Optimizing the design of silica coating for productivity gains during the TIG welding of a 304L stainless steel, Materials \& Design, Volume 28, Issue 9, (2007), pp. 2387-2393

[7] S. Sire and S. Marya, New perspectives in GTA welding of carbon steels by the use of silica, Int. Jl. of Forming Processes, Vol. 3 (2000), pp. 279-301

[8] S. Sire and S. Marya, On the development of a new flux bounded TIG process (FBTIG) to enhance weld penetrations in aluminum 5086, Int. J. of Forming Processes, Vol.5, (2002), pp. 39-51 